\title{
Study on Curriculum Provision for Preschool Education Major in Colleges
}

\author{
Honglei Liang \\ Hainan Tropical Ocean University, Sanya Hainan, 572022, China
}

Keywords: Preschool education major; Goal, Provision, Principle, Learn, Suggestion.

\begin{abstract}
The preschool education is the cradle cultivating front-line teachers, so the quality of curriculum provision directly affects teachers' ability and quality and the enhancement of quality of preschool education is the key factor. Based on the core issue of curriculum provision of preschool education in colleges, this paper mainly discusses the establishment of goal of curriculum provision and the basic principle for curriculum provision and gives suggestions on optimization of the development of professional talents in our country by learning from the practical experience in curriculum provision of preschool education in colleges abroad.
\end{abstract}

\section{Introduction}

The image of preschool children teacher has been gradually built through 3 transformations. Meanwhile, the college preschool education major which cultivates children teachers is also created accordingly; various course patterns and the reflection patterns of knowledge and skill practice provided specially for the major have also been created. In the practice process of college education in recent years, the preschool education gradually becomes mature and systematic and the course reform arising herefrom is also deepened continuously. Therefore, it is necessary to discuss it in this paper to give suggestions for the future benign development of the major.

\section{Goal of curriculum provision of preschool education in colleges}

The goals of curriculum provision should be regarded as an important concept in the modern theory of teaching course; namely, during the design and development of curriculum, there should be specific requirements for its goal to be realized and the expected degree of development of students in all aspects of their quality. As for the preschool education major in colleges, it is believed that the following two principles should be followed when setting the goal of curriculum provision.

\section{People-oriented}

It is a basic requirement that education must be people-oriented. This nature also determines the viviparous relationship between college education and humanism. China's ideological and political education emphasizes the educational ideology of "integrated development" of Marxism, so the goal of humanistic education is also to attain the integrated development of human and make people to grow into themselves, who not only have cognition, skills and other intelligence factors but also have feelings, attitude and other emotional factors. Namely, use the "cultivation aiming at enriching human nature" as the basic principle of curriculum provision of preschool education, pay attention to differences among children and gradually realize the diversified development of curriculum provision. It's worth noting that the preschool education in colleges doesn't aim to cultivate students to become perfect people but aims to integrate their "fragmented" living habits and knowledge phenomena based on the young generation's personality traits, interests and values in today's society; 
besides, it also designs an education and training system and provides relevant teaching courses based on this so that humanistic education can be really achieved.

Thus, it can be seen that humanistic education, which is also the fundamental connotation and final goal of curriculum provision of preschool education in colleges and the ultimate value orientation of modern education, must become the core concept of curriculum provision in colleges, which must train the future high-quality kindergarten teachers by regarding it as a key point, focus on cultivating their professional emotion and attitude, and comprehensively analyze the intelligence, physical strength, emotion, ethics and other aspects to guarantee the diversified development of curriculum provision.

\section{Standard-based}

As for preschool education in colleges, different course systems can be provided for it from different research perspectives. If courses are provided from the perspective of mastery of knowledge, the knowledge-based preschool education curriculum can be formed. If courses are provided from the perspectives of teaching activities and teaching technologies, the ability-based preschool education courses can be formed. Nowadays, China has promulgated a professional standard for preschool education teachers, which has helped to form a series of brand-new orientations and standards for curriculum provision for the preschool education in colleges of China; besides, it aims to fully carry out and implement the spirit of China's educational plan and centers on the construction of a high-quality professional teaching team. To be specific, it also includes the Professional Tentative Standard for Kindergarten Teachers the Ministry of Education issued in 2012. The standard clearly points out that all colleges providing preschool education should actually give important bases for the cultivation of future preschool education talents, use curriculum as the basic guarantee to realize the goal of talent cultivation, consider the preschool education major in colleges as the main place to cultivate the future kindergarten teachers, improve the talent cultivation schemes step by step based on the standard, and realize the comprehensive reform in the educational teaching mode.

According to this paper, as for preschool education in colleges, it is required to solve issues from three dimensions including the professional concept and teacher's ethics, professional ability and professional knowledge, and build a complete course system subject to the 14 fields or basic requires mentioned in the standard. Besides, guarantee that each dimension has its targeted course module, can realize various educational functions and can enrich students' each professional knowledge and ability of kindergarten teacher in the future. For instance, we can combine each course in the curriculum module of liberal education and the practice curriculum module of professional education to form an integrated "professional resultant force of preschool education", and continuously make innovations and progress by closely following the trend of national curriculum reform of preschool education in colleges ${ }^{[1]}$.

\section{Main principles of curriculum provision of preschool education in colleges}

As for the curriculum provision of preschool education in colleges, it is required to take the diversified route emphasizing foundation and encouraging innovation, enhance talent cultivation in moral traits and professional ability, and follow the 4 major principles below. Expand based on the core of public basic courses to enhance teachers' professional quality The preschool education major in colleges should make efforts to set public courses, comprehensively consider the comprehensiveness of knowledge fields covered by such courses, and allow students to learn from the most fundamental natural science and then to gradually learn the social science. Such courses should cover more professional common senses. Meanwhile, public courses should also establish a correct world view and value for students so that they can deepen their cultural deposits in the public basic courses, comprehend more philosophies of life at the philosophical level and become more open-minded. For example, it is required to add more courses concerning foreign literature in the public basic courses to expand their horizon and to help them 
learn the related context of foreign educational development; besides, enhance the importance of public courses so that they can become necessary parts in professional education. As expressly specified in China's standards for preschool education major, an excellent kindergarten teacher shall have good teacher's ethics and this is also the big precondition for being a teacher. Thus, using the public basic courses as the core can undoubtedly expand students' scope of knowledge, strengthen their future professional quality, and guarantee that they will become excellent educators of good character and good behaviors after they become teachers in the future.

\section{Enhance students' scientific research ability by using the setting of basic courses as the strengthening target}

Basic courses for education should give professional demonstration for the students majoring in preschool education and help the smooth development of basic theoretical courses of preschool education teaching. Preschool education is grade- 2 disciplines of educational major. The basic courses of education are very important for the cultivation of future kindergarten teachers, because they not only uphold the cultivation of basic educational theory but also are integrated with more content of training of scientific practice and expand the educational scope of current educational basic courses. Many foreign countries such as America assign 1/4 course hours to the basic courses of education, indicating that the teacher-training universities in developed countries pay more attention to cultivation students' foundation for the purpose of constantly improving and perfecting students' comprehensive quality. In this way, students can become qualified kindergarten teachers in the future.

\section{Use the setting of elective courses as knowledge enlargement to enhance students' diversified knowledge reserve}

Elective courses are of great importance for students majoring in preschool education, because the graduates of many majors have been puzzled about employment in recent years. The root is that they only have single ability, don't expand their ability of knowledge in many fields during college and don't master more skills; the lack of them is very harmful to professional students' long-term development. Therefore, colleges should provide more elective courses which meet their interests, hobbies and social needs for students majoring in preschool education, cultivate their diversified special skills, organize all sorts of elective courses in combination with the characteristics of talents needed by the kindergarten, help them to learn professional skills when learning elective courses, exploit their potential from the perspective of their interest, and thus offer sufficient guarantee for them to become various kindergarten teachers after graduation.

\section{Use the setting of probation and practice courses to strengthen ability and cultivate students' introspection ability in education}

The author thinks that the curriculum provision of the major should show the characteristic of double specialties. Thus, it is required to train students' disciplinary knowledge and specialized knowledge about education and teaching. Dewey, an American educationist, said: "teachers and scientists master different disciplinary knowledge. Scientists can apply the disciplinary knowledge to their experiments directly while teachers can only convey knowledge which they have internalized and comprehended first to the learners in a way they can accept." According to Dewey, we know that teachers' process of knowledge internalization and imparting can never be a pure process of knowledge instruction but a complicated conversion process is needed. As for the preschool education major, it is to train students to learn such a conversion process. Thus, they should be given more time and space to practice, adapt themselves to such a conversion process in real posts of kindergarten teachers, and become a harmonious whole with children, so that they can naturally internalize and convey teaching knowledge and develop an occupational inertia. In the junior and senior years of the major, colleges should organize and give more such probation and practice opportunities to students, and, meanwhile, provide corresponding guidance courses to teach them the 
ability to internalize and impart knowledge. Besides, in combination with their internship experience, they can mutually integrate theoretical knowledge with practical experience and fully cultivate and enhance their professional quality ${ }^{[2]}$.

\section{Enlightenment from the practical experience in curriculum provision of preschool education major in overseas colleges}

In America, students majoring in preschool education can work in kindergartens and preschool education institutions and teach all courses only after obtaining the K-3 teacher qualification, so such students must have a wide range of knowledge, including humanistic knowledge and the knowledge of natural science etc. before work. If a graduate feels a lack of knowledge in a certain field after becoming a kindergarten teacher, he may go back to university to relearn the professional courses regarding this aspect to make up for his defect in work. Generally speaking, America's preschool education has basically realized the joint construction of two paths in the specialized course teaching. The first path is to design student-centered specialized courses and attain the unity of knowledge and practice. To be specific, the curriculum design for preschool education major in America is mainly centering on theme reading, and uses project-based teaching as its core. The two curriculum design modes provide students with more space to think and mainly aim to cultivate them to have the consciousness of problems in learning and work and clearly know their skills and shortages. Therefore, at the beginning of each semester, specialized course teachers provide students with a document of course materials, including the teaching outline of the semester and specialized materials students need to read every week. The reading guidance consists of books and website resources recommended by teachers. After attending the required and elective theoretical courses at ordinary times, students may arrange their self-study based on the planned content supplied in this material package, so every American student majoring in preschool education learn different knowledge in the same semester. The teacher plays a significant role here because he provides each student with course resources at different stages and levels, gives instructions in combination with students' own characteristics, and supports them to develop in a direction applicable to themselves. This can also help to cultivate different types of kindergarten teachers in the future and enrich the course of diversified development of kindergarten teacher system.

The second path, which is "cooperative teaching system", covers educational probation, off-campus courses and on-site experience courses etc. The core content of the "cooperative teaching system" is that one teacher guides $4 \sim 5$ interns and cooperates with another teaching assistant to jointly build a research laboratory. The setting of such course teaching, which follows the "great college" mode in developed countries, makes the teaching process more targeted and refined. In such a mode, the preschool education can basically realize group teaching and parallel teaching modes; besides, in different teaching modes, teachers and students can exchange their roles; the observation report of students' teaching activities based on the mode and the corresponding evaluation standards will be stricter ${ }^{[3]}$.

\section{Suggestions on optimization of curriculum provision of preschool education major in colleges of China}

Firstly, as for the setting of public basic courses, it is required to extensively involve natural science, social science and humanities, arrange such courses and consider extending the duration of such teaching courses. Besides, extensively provide elective subjects regarding art, society, literature, history and philosophy to cooperate with the overall development of required courses so that students can learn the world comprehensively, establish correct values, obtain special skills and thus gain a foothold in the future social competition.

Secondly, pay more attention to the reasonable setting of specialized courses, which shall be dominated by the work core of kindergarten teacher, and achieve the "combination of child care and 
education" in curriculum provision of preschool education; namely, simultaneously strengthen the connotations of child care and education in course content. Thus, the author suggests that colleges provide Children Hygiene in the curriculum of preschool education in colleges so as to review childcare and education for children from the perspective of medical health and cultivate students' practical ability in childcare and education. For example, teach them some commonsense childcare knowledge on daily living, diet, washing and diseases etc. Meanwhile, pay attention to the details during children's living and learning in curriculum provision, and provide psychology and physiology courses so that students can learn the minor details of children's life more comprehensively and can learn all educational content.

\section{Conclusion}

As the main place to cultivate front-line teachers, the preschool education major in colleges should assume more responsibilities for the development of preschool education system, train students' knowledge reserve and skill reserve from diversified perspectives, meet the practical needs in the future field of kindergarten teachers with targeted content of curriculum provision, help students to realize their dream of becoming qualified kindergarten teachers, and lay a early theoretical and practical foundation for them to fully adapt to the needs in the occupational area.

\section{References}

[1] Zhao Dingding. H Case Study on Curriculum Provision of Preschool Education Major in Teacher-training Universities. Huaibei Normal University, 2014.8-10.

[2] Yang Jiafeng. Study on Curriculum Provision of Undergraduate Preschool Education Major in Colleges of Heilongjiang Province--Viewpoint based on the Professional Standard for Kindergarten Teachers (trial). Harbin Normal University, 2015.40-41.

[3] Peng Hailei. Practical Characteristics of Curriculum Provision of Preschool Education Major in America's Colleges. Journal of Beijing Open University, 2013(2):34-37. 